\title{
Mulheres de Corpo e Alma: Aspectos Biopsicossociais da Meia-Idade Feminina
}

\author{
Maria Elizabeth Mori ${ }^{1}$ \\ Vera Lucia Decnop Coelho \\ Universidade de Brasília
}

\begin{abstract}
Resumo
Este trabalho investigou na literatura científica os aspectos biológicos, psicológicos e socioculturais que se estão em jogo na etapa da meia-idade feminina a fim de melhor compreender a vivência dessa mulher. O evento da menopausa - caracterizada pela cessação da ovulação e por manifestações físicas e psíquicas - marca este momento vital e impõe questões que, se não forem bem trabalhadas, podem, no limite, ocasionar sintomas depressivos. As mudanças hormonais condicionam o processo de envelhecimento que aponta para a finitude. Um certo estranhamento em relação a si mesma faz com que muitas mulheres tenham dificuldades em lidar com as perdas inerentes a esta fase de vida.

Palavras-chave: Meia-idade feminina; menopausa; envelhecimento; finitude.
\end{abstract}

Women in Body and Soul: Biopsychosocial Factors in Menopause

\begin{abstract}
This study investigated biological, psychological and sociocultural aspects that interact in middle-aged women in order to better understand their feelings and experiences. The advent of the menopause- characterized by the end of the menstruation and by psychic and physical manifestations- imposes fundamental questions that, on the limit, may elicit depressive symptoms. Hormonal changes are implicated in the aging process, that point to the finitude. A feeling of not being themselves makes many women experience difficulties with losses inherent to this life period.

Keywords: Middle-aged women; menopause; aging; finitude.
\end{abstract}

"Vocês não tinham outro tema mais interessante para investigar?", "Nossa... que graça vocês vêem neste assunto?", "Tudo bem, mas... vamos mudar a conversa?".

Ouvimos frases como as citadas acima quando comunicávamos o tema de pesquisa que estamos desenvolvendo no contexto de uma universidade pública brasileira sobre o período da meia-idade feminina. Além das manifestações de insatisfação sobre o assunto, as declarações sempre eram acompanhadas de expressões negativas que demonstravam muito bem que se tratava de alguma coisa sobre a qual não se devia falar!

Contrariamente ao que se podia ouvir de algumas mulheres, jovens e homens de meia-idade, filhos, maridos e colegas daquelas, diziam: "Interessante, vocês não pensam em nos entrevistar para saber o que nós pensamos sobre elas?", "Lá em casa, desde que minha mãe entrou na menopausa, tudo está mudando...", "Minha mãe não é mais a mesma depois que fez 50 anos", "Tenho percebido, nas reuniões de trabalho das quais participo, que as mulheres mais velhas estão sempre se abanando e pedem para que as

\footnotetext{
${ }^{1}$ Endereço para correspondência: SHLN Setor Hospitalar Local Norte bloco K Centro Clínico Norte I, sala 407, Brasília, DF, 70770 550. Fone: (61) 3476994/ 99892076.E-mail: bethmori@terra.com.br
}

janelas fiquem abertas ou que os ventiladores e os aparelhos de ar-condicionado fiquem ligados. Tem algo a ver com a idade delas?".

Essas falas sugeriam que alguma coisa de muito especial acontece na meia-idade das mulheres e que algumas delas não querem falar desse tema no espaço social de nosso cotidiano. Tais questões indicavam que refletir sobre esse momento da meia-idade feminina era necessário, não devendo ser evitado, como se podia supor. Sabemos, como psicólogasclínicas, que não querer falar não significa não precisar falar. Acaba-se falando, queixando-se aqui e acolá...

$\mathrm{Na}$ experiência clínica era possível identificar, a partir da escuta de algumas mulheres, rico material produzido por elas. A percepção de uma certa perplexidade vivenciada por elas nos levou a identificar na literatura contemporânea os aspectos biopsicossociais da meia-idade feminina que se potencializam nessa etapa da vida, como veremos a seguir.

Este artigo busca, portanto, ampliar a compreensão sobre a meia-idade feminina nesses aspectos aos quais as mulheres estão subordinadas. A ocorrência simultânea destes contribui para que o momento seja vivido de maneira conflituosa.

\section{A Mulher Conta a sua História}

Estudos de gênero têm tomado a mulher como objeto de pesquisa e têm demonstrado diferentes modos de 
construção da subjetividade feminina a partir da inserção social das mulheres em diferentes culturas descritas como patriarcais (Sanchez \& Roel, 2001). Nestas sociedades o momento atual tem se caracterizado por transformações nas quais muitas mulheres têm atuado como protagonistas. Papéis sociais que estavam restritos aos homens, como, por exemplo, o de provedor financeiro da vida familiar, já são exercidos pelas mulheres em muitas culturas.

No Brasil, o resultado da Pesquisa Nacional por Amostra de Domicílios, do Instituto Brasileiro Geografia e Estatística (IBGE) chama atenção para essa transformação: "Apenas entre 1996 e 1999, a proporção de chefes mulheres em famílias de classe média com presença feminina passou de 9,56\% para 12,08\%" (Pnad-IBGE, 2001, p. 39). Em 3 anos, mulheres chefes de família, que eram 917 mil, passaram para 1.305.000, ocorrendo uma expansão de $42 \%$.

Assim, com o passar do tempo, a mulher tem saído do espaço privado e, cada vez mais, ocupa o espaço público que deixa de ser exclusivamente masculino. $\mathrm{O}$ inverso também tem ocorrido: os homens, cada vez mais, desempenham papéis que eram exclusivamente femininos. Essa situação tem contribuído para a redução da hierarquia entre os dois sexos. E, segundo Diniz (1999), os estudos de gênero têm contribuído para demonstrar que "as características, os traços, os comportamentos e os papéis de homens e mulheres não são produtos da biologia e muito menos naturais" e sim "atribuição cultural feita a um e a outro sexo" (Diniz, 1999, p. 179).

No entanto, estamos longe de conseguir uma igualdade entre os sexos. Estudos demográficos demonstram "o quanto é duro nascer e ser mulher" (Del Priore, 2001, p. 81) em diferentes partes do mundo. $O$ estatuto das mulheres ainda é inferior ao dos homens e o tamanho das desigualdades varia de sociedade para sociedade. O preconceito contra mulher se manifesta de modo diverso: acesso desigual à educação, ao mercado de trabalho e à participação na vida pública; infanticídio de meninas e violências específicas, como a excisão de partes da genitália praticada em alguns países, o estupro e a morte decorrentes de guerra, entre outros exemplos.

Vê-se, portanto, que o lugar que a mulher ocupa na sociedade é marcado por avanços e retrocessos. No Brasil, por exemplo, da colônia aos nossos dias, a história das mulheres revela transformações marcadas por "tensões, contradições e negociações que se estabeleceram em diferentes épocas, entre elas (as mulheres) e o seu tempo, entre elas e a sociedade na qual estavam inseridas" (Del Priore, 2000b, p. 84).

Sanchez e Roel (2001) afirmam que as mudanças sociais estão influenciando o modo de envelhecer da mulher. Se antes o papel de passividade aprendido, o mandato de estar a serviço dos demais, com o desconhecimento dos próprios desejos, pôde levar a mulher mais velha a desempenhar fortemente o papel de avó, hoje o envelhecimento tem sido, para algumas mulheres, tempo de realização de sonhos e desejos postergados. Essas mulheres ocupam-se de si mesmas e saem do lugar de resignação que até então lhes era imposto.

Assim, para Sanchez e Roel (2001), o envelhecer é determinado não só pela cronologia, mas também pela condição social na qual se encontra a pessoa em questão, além de ser um processo fortemente afetado pelas singularidades individuais. Esta perspectiva aponta para a inter-relação de aspectos biopsicossociais na meia-idade feminina. As mudanças corporais, previstas no processo de envelhecimento, impactam a auto-imagem feminina e potencializam um sofrer psíquico segundo a visão de cada sociedade em relação à mulher de meia-idade. Nas ocidentais, a história das mulheres tem passado pela história de seus corpos, cuja tríade da perfeição física - juventude, beleza e saúde - tem trazido conseqüências psicológicas cada vez mais séria no enfrentamento do processo de envelhecimento (Del Priore, 2000a).

Para Faria (1995) são "esses anos a mais, com sua variedade de opções que suscitam a necessidade de esclarecer melhor a problemática da mulher madura” (p. 5). Dessa forma, a questão da meia-idade feminina pode ser abordada como uma temática fisiológica - caracterizada pela não possibilidade de procriar - e como uma temática psicológica e social início de grandes mudanças familiares como afastamento dos filhos, dos pais idosos, irmãos, viuvez, e culmina com a adaptação à aposentadoria, senão a própria, a do marido, além de uma aterradora dificuldade, no que se refere à sobrevivência econômica e de participação no mercado de trabalho. Segundo esta autora, compreender então o fenômeno da maturidade feminina é fundamental, pois aproximadamente $1 / 5$ da população feminina no Brasil pode chegar a vivenciar esta etapa da vida, com suas conseqüências biológicas, psicológicas e sociais. E, conforme nosso processo histórico tem demonstrado (Del Priore, 2000b), essas mulheres estarão atuando fortemente na transformação de nossa sociedade.

Ramos (1998) alerta para o fato de que as mulheres têm ficado ao sabor das "decisões científicas" e quase não têm desenvolvido um conhecimento sobre si. Assim, acredita que a participação das mulheres em grupos de vivências deve ser estimulada por profissionais de saúde. Para esta autora, cabe a estes incentivar a troca e o compartilhamento de experiências a fim de que sejam construídos saberes acerca das crises naturais vivenciadas pelas mulheres, tais como: menarca, menstruação, gravidez, parto, menopausa e sexualidade. Tratam-se de espaços de troca e reflexões, 
oportunidades de verbalização e outras formas de expressão de sentimentos e sensações, muitas vezes não elaborados conscientemente. Para Greer (1991/1994) e Ramos (1998) a menopausa seguirá sendo objeto de especulações e interesses mercantis e se afastará cada vez mais da verdade e dos ensinamentos das experiências vividas aqui e acolá "enquanto as próprias mulheres não começarem a contar as suas histórias, o que sentem e como sentem" (Ramos, 1998, p. 19).

\section{O Corpo se Transforma: Menopausa e Climatério}

A mulher, diferentemente do homem, vivencia um evento fisiológico marcante na fase da meia-idade: a menopausa. Segundo Greer (1991/1994), este termo foi cunhado por C.P.L. Gardanne a partir de estudo realizado, em 1812, sobre esta fase da vida. Este ginecologista francês somou duas palavras gregas que significam mens $=$ mês e pausa $=$ parada . A menopausa, então, é o último período menstrual do ciclo reprodutivo feminino. De maneira geral, os autores tendem a defini-la após 12 meses de cessação da menstruação, para ter certeza razoável da não-ocorrência de sangramento menstrual.

Para Trien (1986/1994) menopausa não é doença. No entanto tem sido tratada como tal por muitos profissionais da saúde fortemente influenciados pelas propagandas da indústria farmacológica. Sabe-se que a intervenção medicamentosa indiscriminada pode trazer malefícios à saúde da mulher. E, segundo Paltiel (1993, citado em Diniz, 1999), é durante a meia-idade que as mulheres são mais medicalizadas com psicotrópicos.

Ramos (1998) também reage contra as idéias daqueles que se beneficiam dessa visão de menopausa como doença. Para ela, esse momento é mais uma etapa natural da vida das mulheres, com oportunidades de crescimento e de reavaliação. Opções passadas, atuais e futuras podem ser reconsideradas sob o prisma de novas necessidades.

Profissionais da área da saúde têm utilizado o termo climatério (palavra grega klimakter significa crise) em vez do nome já consagrado menopausa, para se referirem a este momento da meia-idade feminina. No entanto, conforme relatório utilizado pelo grupo técnico de pesquisa sobre menopausa, publicado pela Organização Mundial de Saúde (OMS/WHO, 1996, citada em Menegon, 1998), há sugestão de que o termo climatério deve ser abandonado, pois tem sido associado à sintomatologia, à doença, como vimos em Fechtig (1998/2000). A OMS recomenda a eliminação de prefixos, sufixos e adjetivos para se referir a um momento característico como pré-menopausa, peri-menopausa, pósmenopausa. E orienta também que deve ser utilizada a palavra menopausa para referir-se ao fenômeno como um todo e não só ao cessar do fluxo menstrual. No entanto, a ampla aceitação médica do termo climatério pode ser demonstrada pela nomeação de Programa do Climatério aos trabalhos voltados à saúde da mulher de meia-idade desenvolvidos na rede pública hospitalar, em geral. Os encartes e as publicações gratuitamente distribuídos pelos laboratórios farmacêuticos também utilizam esse termo.

Talvez o fato do evento da menopausa ser caracterizado por uma sintomatologia própria induza os profissionais da área de saúde a associá-la com a doença e não como uma etapa natural do ciclo de vida feminino, não necessariamente patológica. E a prescrição da ingestão dos hormônios (estrógeno e progesterona) tem contribuído para a construção de uma imagem negativa em relação à queda hormonal na fisiologia feminina, que deixa de ser percebida como algo natural e característico por que passam todas as mulheres.

Greer (1991/1994) suspeita que a "síndrome do climatério" é culturalmente determinada e sua gravidade influenciada por outros fatores: ambientais, socioeconômicos e psicológicos. "Uma coisa, entretanto, parece certa: a história comprova que as mulheres que buscam nos médicos a solução para os complexos problemas a serem superados durante o climatério têm sido as mais desafortunadas" (p. 102).

Também para Menegon (1998), a menopausa é um fenômeno fisiológico natural, não isento de um processo de construção social que apresenta variações tanto no espaço quanto no tempo. Segundo essa autora, a circulação de idéias sobre a menopausa tem transcendido as conversas entre mulheres, mídia e produção científica, podendo emergir nas mais variadas situações: literatura, religião, artes plásticas e cênicas.

Menegon (1998) realizou levantamento histórico sobre o sentido da menopausa nas conversas cotidianas e nos relatos científicos. Registros mais antigos sobre este evento referem-se ao período clássico, Roma e Grécia, e medieval, Europa, nos quais o cessar de sangue menstrual não possuía um nome específico, sendo descrito apenas pela presença ou ausência do sangue. $O$ que se tem são referências à idade sobre o início e o fim do ciclo menstrual e listas de remédios para liberar a retenção do mênstruo. Fica claro o sentido atribuído ao término do ciclo menstrual restrito ao fim da capacidade de procriação. O sangue era marcado por contradições, incluindo simbolismos que incluíam o bem e o mal. A retenção definitiva do sangue menstrual estava bastante colada à idéia de envelhecimento. Até o século XVIII, a idéia de que o sangue - poluído e carregado de toxinas - uma vez retido no organismo, provocaria sua destruição interna, redundando no envelhecimento e degeneração de órgãos.

Ainda sobre o sangue menstrual, Borysenko (1996/2002) enfatiza que o ciclo vital feminino tem sido tradicionalmente estudado em função dos "três mistérios do sangue" menarca, parto e menopausa. Esses três eventos fisiológicos assinalam transições entre três fases da vida reconhecidas 
desde os tempos antigos - virgem, mãe e velha. "Essa natureza tripartite do ciclo vital fazia sentido, fisiologicamente falando, até tempos recentes" (p. 22). E é antiga a associação entre distúrbios de comportamento e função reprodutiva da mulher. Geralmente esses males eram expressos pela palavra histeria, derivada do grego bustera (útero), associação encontrada em papiro egípcio de 1900 a.C., em que os distúrbios de comportamentos tinham como explicação o deslocamento uterino. Nos escritos hipocráticos existe a idéia de útero errante como o grande causador das misérias e loucuras femininas. No entanto, conforme Greer (1991/1994), Nissim e Araújo (2001), Ramos (1998) e Trien (1986/1994), a maioria das mulheres passa por esta etapa da vida sem grandes transtornos, enquanto outras se ressentem muito por apresentarem queixas físicas e psíquicas.

Segundo Simões e Baracat (1999), os sintomas neuropsíquicos são os primeiros a surgirem e estão representados principalmente pelos distúrbios vasomotores. Estes, segundo estudos epidemiológicos, acometem 75\% das mulheres. Caracterizam-se pelo aspecto vasodilator representado pelo sintoma de calor e pelo sinal de rubor e, a seguir, pela vasoconstrição referida como um calafrio e notada como sudorese. Os locais do corpo que mais são acometidos são o tórax, o pescoço e a face. A duração, a freqüência e a severidade variam de mulher para mulher. Podem ocorrer espontaneamente. No entanto, sabe-se que podem ser desencadeados pelos alimentos calorigênicos, bebidas alcoólicas, alguns medicamentos e temperatura do meio-ambiente e, particularmente, por situações de estresse físico ou emocional. A presença desses distúrbios é acompanhada de taquicardia e ansiedade. Essas situações "desestabilizam as mulheres, determinam disfunção em seu ritmo de sono-vigília, predispõem-nas à fadiga e à irritabilidade, expõem-nas a respostas de ampla labilidade emocional" (Simões \& Baracat, 1999, p. 374).

Algumas mulheres apresentam também cefaléia, ansiedade, depressão, fadiga, insônia, diminuição da libido, secura vaginal, dores articulares, dores nas pernas, osteoporose, perda parcial da memória, cabelos brancos, ganho de peso geral e localizado, dentre outros. No entanto, diversas autoras (Greer 1991/1994; Nissim \& Araújo, 2001; Ramos, 1998; Simões \& Baracat, 1999; Trien, 1986/1994) argumentam que toda essa sintomatologia caracteriza o processo de envelhecimento normal.

Já para Fechtig (1998/2000) as queixas são sinais específicos de uma 'doença' do climatério. Este médicoginecologista reserva um capítulo de seu livro para abordar cada um desses sintomas. Como tantos outros médicos, esse autor reduz a complexidade do fenômeno da menopausa que se encontra inserido no momento da meia-idade feminina com suas implicações biopsicossociais. $\mathrm{Na}$ tentativa de combater um certo mal-estar físico e psicológico, característico e passageiro desse momento de vida da mulher, muitos médicos transformam as queixas ouvidas nas consultas ginecológicas em uma doença, cujo tratamento deve ser à base de hormônios e antidepressivos.

Segundo Furtado (2001), o corpo enquanto lugar de memórias que emergem na sintomatologia psicossomática serve, também, de suporte para um eu coeso. Ao interrogar o sentido que algumas mulheres davam à menopausa, em pesquisa realizada, a psicanalista pôde perceber a dificuldade da mulher em definir esta experiência. Esse momento a faz entrar em contato com sua história pregressa.

Falar sobre a menopausa parece ter propiciado um movimento de olhar para o corpo e para o passado, em que se tentava acessar, por meio da linguagem, sentidos intensamente recalcados em suas experiências entre o vivido e o que pode dele ser dito. (Furtado, p. 33)

A autora, ao valorizar a interatividade da relação mãebebê como criadora do sentido do Eu, aponta para as trocas ocorridas nesta relação como as que moldarão as relações da menina com o mundo, sendo a feminilidade o resultado de um processo identificatório cheio de nuances psicossomáticas.

Para Furtado (2001) essa primeira relação mãe-bebê é um "nicho intocável, derivado das marcas corpóreas primitivas, o que resulta na constituição de realidades psíquicas singulares, pré-simbólicas, que deverão ser re-significadas, simbolizadas, portanto, na relação transferencial com o analista" (p. 30). Dessa maneira, as sensações desconfortáveis e dolorosas presentes no corpo ao longo da vida e acentuadas no momento do climatério, apontam para uma exacerbação sensorial que se manifesta pelos calores, insônias, mudanças na pele e no volume corporal. O fim desta etapa, caracterizado pelo "reequilíbrio do corpo a um novo patamar de funcionamento, coincide com o alívio que acompanha sua percepção da integridade corporal" (p. 33).

Assim, uma sintomatologia psicossomática representa a sensorialidade primária ressurgida no climatério, momento de perdas e desconfortos, potencializado pela fragmentação do $e u$ coeso. A restauração de uma imagem corporal integrada só se dará pelo reasseguramento da capacidade de amar e ser amada. Daí a importância do incremento da utilização de recursos relacionados ao autocuidado de forma menos persecutória. Os cuidados pessoais auxiliam na aquisição de um sentido auto-erótico que antecipará o direcionamento do investimento libidinal para um outro. Trata-se de "erotizar livremente um corpo que não perdeu a possibilidade de ancorar o desejo" (Furtado, 2001, p. 33). 


\section{Os Hormônios: A "Pedra Filosofal" da Mulher e a Terapia de Reposição em Questão}

Sob o ponto de vista fisiológico, a menopausa é a cessação da ovulação. A mulher já nasce com o seu potencial reprodutivo. A maioria dos óvulos, que na $30^{a}$ semana de vida de um embrião feminino chegam a ser seis milhões, em pouco tempo degenera de modo que apenas cerca de um milhão estão presentes nos dois ovários por ocasião do nascimento e apenas 300 mil a 400 mil na puberdade. A seguir, durante todos os anos reprodutivos da mulher, entre os 13 e os 46 anos de idade, cerca de 400 folículos desenvolvem-se o suficiente para expelir seus óvulos - um a cada mês, e os restantes degeneram.

Assim, automaticamente os óvulos vão desaparecendo. "É um processo que quem esclarecer vai encontrar a 'pedra filosofal' da mulher. Ainda não há o que fazer para que esse fenômeno da extinção dos óvulos pare!", enfatiza R. R. Costa (comunicação pessoal em 09/11/2001). Segundo esta ginecologista e coordenadora de um programa de climatério no Distrito Federal, as alterações hormonais bruscas demonstram como a fisiologia feminina é extremamente complexa. E, "muito do que se passa no corpo da mulher ainda está para ser respondido pela ciência biológica". No entanto, ela também concorda que não cabe apenas à biologia elucidar a vivência feminina nessa etapa da vida que é mediada pelo contexto sociocultural e também pela história pessoal e familiar da mulher.

A ênfase biológica se manifesta, por exemplo, pela prescrição da TRH, Terapia de Reposição Hormonal. Esta tem sido indicada pela medicina como uma maneira de driblar a natureza fisiológica feminina. Mulheres que se encontram no período do climatério e entrevistadas pela mídia dizem se sentirem mais bonitas (pele e cabelos sedosos) e dispostas para enfrentar as exigências do dia-a-dia de trabalho. No entanto, conforme Kolata (2002), o estudo longitudinal que vem sendo conduzido pelo doutor Jacques E. Rossouw aponta para alta correlação entre estas drogas usadas e câncer de mama invasivo.

Sabe-se que a TRH trata-se de método terapêutico polêmico. Há tempos existem entre os profissionais médicos opiniões favoráveis e posições contrárias ao uso de hormônios. Dentre estes, encontram-se aqueles que insistem na busca de tratamentos naturais (Ramos, 1998). Assim, é compreensível o porquê da TRH ser fonte de preocupação e medo nas mulheres que vivenciam essa etapa da vida.

As informações contraditórias quanto à efetividade da utilização da TRH aumentam as dúvidas sobre a administração desses hormônios (Ciornai, 1999; Nissim \& Araújo, 2001; Ramos, 1998). Além disso, esta medicalização escamoteia a complexidade da menopausa, reduzindo-a um evento de natureza biológica.

\section{O Corpo Amputado: Histerectomia e Ooforectomia}

Ramos (1998) se posiciona com muita cautela em relação às recomendadas intervenções cirúrgicas como a histerectomia e a ooforectomia, extração de útero e ovários, respectivamente. Sabe-se que hoje são altíssimos os custos hospitalares com estas cirurgias. Nos Estados Unidos é a segunda cirurgia de grande porte, totalizando cerca de 576 mil casos por ano. Calcula-se que uma em cada três mulheres norte-americanas com mais de 60 anos não tenha útero. A autora refere-se ao valor de 5 bilhões de dólares anuais com custos hospitalares. Esta médica cita estudos norteamericanos que identificaram que "a maioria das histerectomias é eletiva e que mais de $90 \%$ destes procedimentos ocorrem em mulheres não portadoras de patologias malignas, ou seja, cânceres" (Ramos, 1998, p. 121). Assim, pode haver razões não-médicas que influenciam esses altos índices, tais como: raça, nível sociocultural das pacientes e também a característica do serviço de saúde em questão.

Sabe-se que há implicações na sexualidade da mulher submetidas a essas cirurgias intervencionistas. Loureiro (1997) aponta para as seqüelas psicológicas da histerectomia em mulheres de diferentes camadas sociais e econômicas, com idade entre 25 e 50 anos. Usando expressões como "um corpo-para-a-produção" e "um corpo-para-o-consumo" para referir-se às mulheres de nível socioeconômico baixo e alto, respectivamente, os resultados puderam demonstrar que a classe socioeconômica contribui para o significado e a atribuição de sentidos que as mulheres dão ao próprio corpo e as conseqüências na resposta sexual.

Conforme Ramos (1998), as queixas e os sintomas da menopausa em histerectomizadas são mais intensos e graves; na sua prática clínica, a autora tem encontrado quadros depressivos, de difícil solução. Ela aponta para a questão simbólica do útero: fertilidade e feminilidade. Desequilíbrios fisiológicos, hormonais, anatômicos e, principalmente, energéticos ocorrem, com graves complicações para a vida dessas mulheres.

Atualmente, alguns médicos discutem as conseqüências dessa intervenção sobre a queda da libido. Se antes se pensava exclusivamente em razões psicológicas, agora há comprovação de que existem razões fisiológicas para tais sintomas. A retirada do útero torna os tecidos da região pélvica menos ingurgitados, com menor quantidade de sangue na hora de excitação sexual. Por isso, pode ocorrer uma diminuição do prazer. A ausência do colo uterino também afeta a sensibilidade, o prazer que muitas sentiam quando ele era tocado. A redução hormonal provocada pela retirada dos ovários também influencia na sensação de prazer (Ramos, p. 127).

Além disso, Deutsch (1945/1960) já alertava que mulheres submetidas às cirurgias como a histerectomia, antes de 
viverem a menopausa, apresentavam reações que demonstravam o valor simbólico do aparelho genital. O aumento da agressividade e de estados depressivos era possível ser explicado pela perda dos órgãos reprodutores, o que é equivalente à castração.

\section{O Espelho Negativo}

Greer (1991/1994) e Ramos (1998) referem-se a estudos que apontam que nas sociedades ocidentais as queixas das mulheres que se encontram nesse momento da menopausa são maiores do que as das sociedades orientais. Estas valorizam a experiência de vida de homens e mulheres idosos, que passam a contribuir para a formação dos mais jovens. Reconhece-se que ao longo da trajetória vital o ser humano constrói sentidos e significados acerca do propósito da vida que os habilitam a manter íntegra sua saúde mental, ainda que em situações adversas. A sabedoria do idoso então é valorizada.

Contrariamente, a sociedade brasileira tem assumido os valores característicos da "pós-modernidade" ocidental: "mudanças rápidas de conhecimentos, pelo questionamento de valores, pelo fenômeno da globalização, pela confiança nos sistemas abstratos, pela obsolescência e descartabilidade de objetos, pessoas e relações, com um certo menosprezo pelo valor da vida." (Freire \& Resende, 2001, p. 73). Fazemos parte de uma cultura que valoriza o consumo desenfreado de bens e até de relações, onde o bem maior é a produção. Quem deixa de produzir, deixa de existir! Portanto, o processo de envelhecimento tem sido percebido de maneira pejorativa. Segundo estas autoras, viver e envelhecer atualmente têm sido uma experiência difícil para muitas pessoas.

E a posição "da mulher mais velha" é bem mais desqualificada socialmente do que a do homem, diferentemente de outras culturas, onde elas galgam poder na escala social com o passar da idade. Nestas sociedades, a passagem da vida reprodutiva para a não-reprodutiva não é tão sentida pelas mulheres e a questão fisiológica para elas tem uma importância menor. Nas Filipinas, por exemplo, além das mulheres da meia-idade não relacionarem nenhum sintoma físico ou psíquico à cessação da menstruação, não existe um termo lingüístico para denominar a menopausa (R. R. Costa, comunicação pessoal em 09/11/2001). Estudos realizados em algumas tribos das Filipinas indicam que o Índice Menopáusico de Blatt e Kupperman é zero. Este avalia a presença de 11 sintomas, tidos como característicos da menopausa: ondas de calor, parestesia, insônia, nervosismo, depressão, vertigens, fadiga, artralgia/mialgia, cefaléia, palpitação e zumbido. O primeiro tem peso 4, os segundo, terceiro e quarto sintomas têm peso 2 e aos demais é atribuído peso 1, conforme consta na Ficha de Clínica de Climatério, distribuída pela FEBRASGO (Federação Brasileira de
Ginecologia e Obstetrícia) aos hospitais da rede pública brasileira.

Segundo Sommer e colaboradores (1999), os estudos realizados sobre a menopausa têm contemplado primordialmente mulheres brancas ocidentais. "A cultura onde a mulher está inserida em muito contribui para que a atitude dela seja favorável ou desfavorável" (p. 868). Nas culturas que desvalorizam o processo de envelhecimento e cultuam a juventude, como a ocidental, as reações são mais negativas e, conseqüentemente, ocorre um processo mais sintomatológico. A fim de verificar a correlação entre cultura e sofrimento na menopausa, esses autores realizaram pesquisa com diferentes grupos étnicoraciais sobre a influência das atitudes de mulheres em face à vivência da própria menopausa. O estudo demonstrou que as reações frente à menopausa são diferentes nos grupos pesquisados (afro-americanas, brancas, chinesas-americanas, japonesas-americanas e hispânicas) e são as afro-americanas as que têm uma atitude mais favorável. Assim, parece ser um tanto heterogêneo a maneira pela qual as diferentes culturas lidam com a menopausa.

Assim, na cultura ocidental cujo paradigma valoriza a juventude, as condições físico-psíquicas da menopausa tornam-se fragilizadas ainda mais pelo envelhecimento do corpo, fazendo com que a questão da finitude se apresente para as mulheres. Goldfarb (1998) refere-se à estranheza ante a própria imagem que a mulher de meia-idade vê diante do espelho. A autora conceitua este fenômeno como "espelho negativo" que acontece na maioria dos casos antes da velhice se instalar e que a anuncia sob o ponto de vista estético, correlacionando a "funcionalidade do corpo e o significado social que cada cultura outorga a essa fase da vida" (p. 54).

Furtado (2001) enfatiza que a experiência da menopausa vivida na meia-idade feminina relaciona-se às diferentes maneiras de se lidar com a "ameaça à integridade narcísica" (p.34). Pois se trata de um momento de vida onde as mulheres lidam com o limite das possibilidades vitais: o processo do envelhecimento, marcado fortemente pelas transformações corporais, se impõe por meio das limitações implícitas e explícitas às realizações pessoais até então possíveis, apontando para a finitude. Na impossibilidade de Ser, muitas mulheres da meia-idade se vêem abaladas na capacidade de Fazer, de atuar no mundo de maneira saudável (Winnicott, 1979/1990,1986/1996).

\section{A Mulher Desejante}

Nos mecanismos de comparação social observa-se diferença de sentido nos termos empregados para se referir aos homens e mulheres maduros, contribuindo para que a relação que a mulher da meia-idade mantém com o próprio corpo não seja a mesma que o homem dessa faixa estabelece 
com o físico. Assim, marcam-se diferenças na maneira de se lidar com o próprio desejo. Os preconceitos sociais em relação a ela são maiores. Fala-se da queda da libido feminina como uma das queixas recorrentes no período da menopausa. Contrariamente, Greer (1991/1994) e Ramos (1998) relatam que muitas mulheres afirmam nunca terem se sentido tão livres sexualmente como nessa fase.

Sobre a questão do desejo sexual na meia-idade, Tadini (2000) empreendeu o primeiro estudo de base populacional sobre a sexualidade na pós-menopausa no Brasil e na América Latina. A pesquisa, realizada com 456 mulheres, que se encontravam na faixa etária dos 45 ao 60 anos, constatou que $68 \%$ das mulheres entrevistadas mantêm atividade sexual e que, dentre estas, $88 \%$ têm prazer na relação. “Os resultados derrubam o mito de que sexo é prazer somente para jovens como Feiticeira e Tiazinha" (p. 10).

Beauvoir (1949/1980) enfatizava que o mundo masculino herdado fez com que a mulher desde cedo investisse nos valores sexuais que detém, procurando "agradar na maior parte dos ofícios que exerce, pois afinal não lhe foi permitido dominar o mundo a não ser por intermédio dele [mundo masculino]" (p. 343). O "horror de envelhecer", então, perturba a mulher muito antes da "mutilação definitiva" (idem). Enquanto o homem vive seus ardores eróticos na mocidade, a mulher por volta dos 35 anos, tendo superado suas inibições, passa a conhecer seus desejos e vivencia sua maturidade erótica. Neste momento, como nunca, desejará satisfazer seus prazeres. No entanto, é a partir daí que a mulher começa a perder seus dotes físicos e a não ser percebida como atraente. Assim, perde o seu domínio!

As alterações fisiológicas ligadas ao aparelho genital, os impactos na sexualidade e o que esta representa sob os pontos de vista psicológico e sociológico - tanto no momento da puberdade quanto no momento do climatério - foram discutidos por Deutsch (1945/1960). Segundo esta psicanalista, a puberdade é uma segunda edição do período infantil, pois nessa fase mobilizam-se antigas relações com os progenitores. Trata-se de um reviver do Complexo de Édipo.

No climatério, uma terceira edição é experimentada e ocorre uma transferência das relações parentais para as filiais. Este momento de vida retoma questões que caracterizaram a puberdade. Antigos conflitos emergem e são revividos no climatério, mas em uma nova forma. "Tanto a puberdade quanto o climatério objetivam construir um presente, a primeira voltada para o futuro e a última com o olho no passado" (p. 429). O declínio das características sexuais secundárias, provocados pela suspensão hormonal, resulta na perda gradual da feminilidade, segundo a autora. A desvalorização que ameaça a genitália, como órgão de reprodução, associado à percepção dos primeiros sinais de velhice, faz com que uma atenção para si seja incrementada. Todas as forças do eu se mobilizam para conseguir um melhor ajuste à realidade.

Percebe-se que Helen Deutsch (1945/1960) não considerou apenas os processos fisiológicos que marcam a mulher na meia-idade, mas igualmente as repercussões psíquicas de tais transformações, a partir da escuta de suas pacientes. No entanto, a perspectiva da autora não contempla a variabilidade de experiências femininas no climatério em função do contexto sociocultural no qual está imersa.

Laznic (2001) também tem se preocupado com a perda da feminilidade nas mulheres da menopausa. "Existe a idéia de que haveria fuga diante de uma demanda pulsional, aumentada e por isso inquietante" (p. 63). A partir das considerações freudianas acerca da equivalência bebê-pênis, esta psicanalista aponta para a perda definitiva das promessas feitas à menina na entrada no Édipo. O fim da menstruação e da juventude realiza o fim da possibilidade de um filho substituir o falo e da falacidade de seu corpo inteiro. "A mulher realiza o duplo luto de não mais poder pretender nem a facilidade do materno nem a de sua beleza" (p. 63).

Consideramos que a relação que a mulher da meia-idade mantém com o próprio corpo, e neste sentido com o desejo sexual, é marcada por fatores de ordem biológica, psicológica e sociocultural. A queda hormonal, a história de vida pessoal e familiar, as experiências afetivas, o lugar social que a mulher ocupa - etnia, raça, classe social, momento contemporâneo - são, por exemplo, aspectos indissociáveis que constituem a experiência subjetiva da meia-idade feminina.

\section{A Juventude a qualquer Preço: Preocupação de toda Mulher?}

Deutsch (1945/1960) acentuava a importância do corpo biológico na constituição do Ser Mulher e a significação da capacidade reprodutiva deste corpo para a sociedade, ao se perguntar sobre o remanejamento econômico do aparelho psíquico que ocorre nas mulheres de meia-idade em funções das alterações hormonais. Para esta psicanalista, o declínio orgânico é uma das tarefas mais difíceis de ser enfrentada na vida de qualquer mulher.

De fato, hoje em dia podemos ver que não apenas as mulheres maduras se preocupam com esta questão. De maneira geral, as mulheres têm buscado alternativas para se manterem mais jovens e atraentes, até mesmo aquelas que são cronologicamente jovens. A imprensa tem veiculado a preocupação da mulher com o seu corpo e as facilidades de correção oferecidas pelos cirurgiões plásticos. Estes combinam tecnologias que aliam o poder do bisturi aos efeitos dos tratamentos dermatológicos de última geração. Compostos de substâncias naturais e sintéticas injetadas sob a pele, ou em sua superfície, eles esticam, incham, afinam, 
clareiam, limam, preenchem e moldam as partes do corpo. A juventude está disponível num par de ampolas, o botox, substância extraída da bactéria que causa o botulismo, que tem a capacidade de paralisar os músculos faciais "alisando" regiões como os cantos dos olhos e os vincos da testa e boca. Assim, a idade tem sido considerada algo completamente relativo.

São os preconceitos sociais em relação à mulher da meiaidade que incrementam a dificuldade de lidar com o envelhecer que está por vir. Ciornai (1999) realizou estudo demonstrando que até mesmo as mulheres de vanguarda, que participaram de movimentos de contracultura dos anos 1960 e 70, como tantas outras que enfrentam a menopausa, confessaram seus medos de não serem mais vistas como vibrantes, excitantes ou sexualmente atraentes.

Beauvoir (1949/1980) já se perguntava “o que será desta pobre mulher que vê a degradação de seu corpo?” Pinturas faciais, mudança na cor dos cabelos, cirurgias estéticas apenas prolongarão sua “juventude agonizante”. E nada mais são do que tentativas de trapacear o espelho, pois o processo de envelhecimento irreversível destruirá "todo edifício construído durante a puberdade" (p. 343). Neste momento se sentirá tocada pela morte.

Miranda (1996) identificou que a menopausa não é a maior preocupação de mulheres da meia-idade faveladas da capital paulista. Segundo a pesquisadora, o discurso dessas mulheres ressalta os seguintes temas: 1) corpo como lugar de sintomas e força de trabalho, e não pela dimensão estética; 2) atividades e emoções: mãe, em primeiro lugar, e esposa ou mulher, em segundo, como trabalhadora, há uma falta de perspectiva profissional; 3) sexualidade: diminuição da libido, pelo mau relacionamento com o parceiro; 4) ambiente de moradia: medo e preocupação; 5) projeto de vida e atitude em relação à vida: esperança de um dia melhor. Miranda pôde concluir que possivelmente devido às condições adversas experienciadas, a mulher favelada não retrata a menopausa como aquelas não submetidas à situação socioeconômica desfavorável.

\section{A Mulher Deprimida e o Envelhecer}

Diante de tantas questões biológicas e socioculturais implicadas, é possível entender o mal-estar psíquico gerado e, quando expressos pela mulher que as vivenciam, muitas vezes são diagnosticados como sintomas depressivos. Talvez isto explique a grande quantidade de estudos que tentam correlacionar as variáveis depressão e menopausa. Soares (2000) cita estudos sobre a correlação entre transtornos mentais e gênero feminino, apontando que o ciclo reprodutivo da mulher tem sido relacionado com a exacerbação de vários transtornos psicológicos, dentre eles: a depressão puerperal, a tensão pré-menstrual e a depressão na menopausa. Segundo enfoque sociocultural, o conceito destes transtornos relacionados ao ciclo menstrual seria algo "construído socialmente" (p. 144). A partir de valores culturalmente aceitos por determinados grupos, a chegada da menstruação leva a mulher ao exercício do papel mais distinto e nobre na fase fértil: o de ser mãe. A dificuldade para aceitar a renúncia da própria vida em prol da maternidade e do papel de esposa condenou muitas mulheres às internações psiquiátricas (Engel, 2000).

Soares (2000) cita que a retenção do fluxo sanguíneo tem sido vista historicamente como responsável pelo surgimento de delírios, alucinações e até mesmo de idéias suicidas. O período da peri-menopausa como a fase de maior risco, "onde as mulheres poderiam 'ver o mundo em chamas, de cabeça para baixo' com a ocorrência de 'congestões cerebrais’ pela retenção de material venenoso” (p. 144). A menstruação foi, sem dúvida, "um dos pontos mais valorizados pelos psiquiatras na construção dos diagnósticos da doença mental em indivíduos do sexo feminino" (Engel, 2000, p. 334).

O artigo de Soares, Almeida e Silva (1995) do Instituto de Psiquiatria do HC-FMUSP sobre a evolução histórica do conceito de melancolia relacionada à fase climatérica, aponta para "imprecisões diagnósticas, heterogeneidade clínicopsicopatológica e repercussões nas propostas terapêuticas" (p. 45), já que ao longo das últimas décadas, a chamada melancolia climatérica não tem encontrado sustentação enquanto entidade nosológica. Não há como caracterizar um transtorno de humor com características singulares e restritas a esse período vivido pela mulher de meia-idade.

No entanto, os três anos que antecedem a instalação definitiva da menopausa têm sido relacionados a uma maior prevalência de transtornos de humor com sintomatologia tanto somática quanto padrões afetivos e comportamentais que se assemelham às descrições de "depressões atípicas". Este momento também se destaca pela história familiar pobre e a ocorrência do primeiro episódio depressivo, conforme estudos apontados por Soares e colaboradores (1995). Segundo estes autores, vários aspectos contribuem para um certo estado de humor depressivo. Além dos biológicos e sociais, a atitude da mulher frente a esse fenômeno em muito contribui para a presença ou ausência de uma sintomatologia depressiva. Dentre os principais sintomas psíquicos atribuídos a este período, encontram-se a perda de autoestima, acompanhada de labilidade afetiva e irritabilidade, prejuízo de adaptação social, dificuldades de concentração e memória, além de queixas relacionadas à esfera sexual, mais especificamente pela perda de interesse sexual devido às dores causadas pela falta de lubrificação vaginal.

Como já apresentado anteriormente, acredita-se que as variações hormonais influenciam os transtornos mentais. Por 
esta razão, além de antidepressivos, a TRH tem sido indicada para o tratamento da depressão. No entanto, segundo Soares (2000), "caracterizar o quadro depressivo em paciente no climatério requer o conhecimento do quadro clínico próprio desta fase, a investigação de possíveis etiologias orgânicas associadas (como patologias de tireóide), além da avaliação clínico-ginecológica detalhada" (p. 153). Os transtornos de humor, principalmente, estão associados à história prévia de depressão, ao pouco suporte psicossocial e ao grande desconforto físico, gerado pelos sintomas do climatério.

Assim, parece-nos correto pensar que as ditas reações depressivas podem ser uma expressão afetiva natural desta fase da vida, já que se trata de um momento caracterizado por fatores psicossociais tais como: alterações nos papéis familiares, mudanças no suporte social, perdas interpessoais, além do próprio envelhecimento físico com suas repercussões clínicas. Neste sentido, ao se considerar não somente as transformações biológicas, mas especialmente, os aspectos psicológicos e os culturais, a condição feminina em si não seria um fator de risco para a saúde mental, conforme questiona Diniz (1999)?

Segundo Goldfarb (1998), as limitações corporais e a consciência da temporalidade são questões fundamentais no processo de envelhecimento e aparecem no discurso de idosos, embora adquiram tonalidades e intensidades diferentes. Isso ocorre devido à estrutura psíquica do individuo e da situação social em que o idoso se encontra originando daí “"múltiplas velhices". Segundo esta psicanalista, a palavra "velhice" parece ter algo da ordem do diabólico, pois não pode ser dita "sem provocar medo e rejeição" (p. 23), cujo sentido está na categoria dos "irrealizáveis" sartreanos, onde "o velho é sempre o outro!" (Beauvoir, 1970, citada em Goldfarb, 1998). Assim, não podemos vero envelhecer em nós mesmos, apenas nos outros, embora estes outros tenham a nossa idade.

Goldfarb (1998), que realizou pesquisa qualitativa com idosos, pôde perceber que é "sempre o outro que repentinamente nos nomeia de velho" (p. 54). E, pensar sobre esse momento da vida parece fundamental para poder melhor encará-lo, segundo propõe uma das mulheres-idosas entrevistada pela psicanalista:

É verdade isso de pessoas que não se reconhecem. Acho que deveria haver nos centros de saúde onde funcionassem grupos de terceira idade, profissionais que desenvolvessem um trabalho com as pessoas de 40 a 50 anos, para orientar sobre como elas vão envelhecer, de que maneira têm que proceder para se aceitar, se olhar mais no espelho, se conhecer mesmo. Tem que ser feito esse trabalho para que as pessoas não sofram tanto assim. (Dona Elzie, 76 anos, conforme citado por Goldfarb, 1998)

\section{A Mulher e a Emergência de Grupos Terapêuticos}

Marraccini (1999) realizou trabalho como o sugerido por Dona Elzie. Para a psicanalista, as mudanças biopsicossociais que as mulheres enfrentam na meia-idade podem conduzilas para processo vivencial crítico. Por isso, a psicanalista decidiu pela criação de espaços de escuta, onde as mulheres pudessem discutir, refletir e elaborar suas angústias e vivências pessoais. $\mathrm{O}$ modelo de intervenção clínica, de duração limitada, procurou abarcar o funcionamento psíquico da mulher madura, seu modo relacional, sua história pessoal e os acontecimentos atuais em sua vida. Sobre esta experiência, a autora nos diz:

Em algumas circunstâncias, constitui potencialidade para o surgimento ou exacerbamento de condições patológicas; enquanto que em outras, possibilidade de desenvolvimento e amadurecimento pessoal. Assim, caso seja possível elaboração construtiva do presente e suas articulações com o passado, estará indicando para um futuro envelhecer criativo, com expressão e sentido. (Marracini, 1999, p. 1)

Marraccini (1999) também procurou ouvir outros profissionais da área de saúde que lidam com o públicoalvo: ginecologistas, endocrinologistas, nutricionistas. Estes confirmaram a importância de uma abordagem multidisciplinar, com a presença de psicólogos, na busca de um atendimento eficaz para a mulher dessa faixa etária.

Publicações sobre menopausa e climatério, como os de Ciornai (1999), Landau, Cyr e Moulton (1994/1998), Ramos (1998) e Trien (1986/1994), também são resultados de trabalhos realizados por elas, em encontros comunitários ou grupos de mulheres de meia-idade. Essas trazem temas e questionamentos que são freqüentemente discutidos nesses espaços, dentre eles: TRH (vantagens e desvantagens), sexualidade (interesse, desejo e implicações físicas como secura vaginal, incontinência urinária, uso de contraceptivos), os já mencionados "sintomas", saúde em geral (ganho e dificuldade em perder peso, dieta com baixo teor de gordura, freqüência de exercícios físicos, prevenção de doenças cardíacas, cigarro, bebida alcoólica, osteoporose, uso de cálcio, vitamina $\mathrm{D}$, uso de laticínios, colesterol), problemas psicológicos (irritabilidade, depressão, crise, estresse familiar, ansiedade, dias "ruins") e cirurgias, como histerectomia e ooforectomia (por que e quando fazer?).

Cabe destacar que boa parte dos trabalhos sobre essa etapa da vida feminina faz parte de pesquisas desenvolvidas por profissionais da área da saúde (psicólogas, médicas e enfermeiras), que estão vivenciando a meia-idade e sentiram necessidade de divulgar o conhecimento construído por elas. São pesquisas realizadas em grupos de vivências e de atendimentos prestados à saúde da mulher. 
Esses trabalhos terapêuticos contribuíram também para que este estudo se ampliasse. Assim, estamos realizando intervenções psicológicas grupais, tanto em espaços hospitalares públicos do Distrito Federal como no Centro de Atendimento e Estudos Psicológicos (CAEP), da UnB (Mori, 2002). A preferência por um processo psicológico em grupo tem se embasado na crença de que a escuta de uma outra mulher inserida num mesmo contexto sociocultural e que esteja vivendo demandas semelhantes possa resultar numa experiência enriquecedora e, também, contribuir para que a vivência da meia-idade se torne um momento menos sofrido.

A acolhida desses trabalhos pelas mulheres-participantes tem ratificado a importância de se implementar metodologias de intervenção psicológica grupal em hospitais públicos, como parte das rotinas de atenção integral à saúde da mulher. Trata-se de uma forma legítima, e conseqüentemente mais saudável, da própria paciente poder falar da própria experiência (Coelho \& Holanda, 2002). Além disso, ao contar a própria história, a mulher estará ampliando o conhecimento científico acerca da existência humana (Del Priore, 2000b).

\section{Considerações Finais}

Vimos neste estudo que fatores de ordem biológica, psicológica e sociocultural estão presentes no período da meia-idade feminina, justificando a atenção clínica e a investigação sobre o fenômeno. A menopausa, que se insere neste período, pode ser palco de sofrimento psíquico, apesar de fazer parte da vida da mulher.

O desequilibrio hormonal da menopausa, acompanhado pela desvalorização estética do corpo e por toda uma sintomatologia física e psíquica - que no limite aparece como sofrimento depressivo - sinaliza o envelhecimento inevitável e a finitude. No entanto, apesar de o corpo feminino ser fortemente marcado pelo ciclo biológico-reprodutivo, o destino da mulher não pode ser reduzido à fisiologia humana. Mudanças provocadas por perdas - saída dos filhos de casa, aposentadoria, relacionamento conjugal muitas vezes desgastado - podem intensificar os conflitos inerentes à subjetividade.

A compreensão do fenômeno da meia-idade feminina nos exige, ainda, considerar aspectos socioculturais, conforme apontados no texto. Na nossa sociedade contemporânea, envelhecer significa distanciar-se da exigência da perfeição do corpo humano, já que a beleza e a juventude são valorizadas como modelo de saúde. Neste sentido, as mudanças físicas e psíquicas que a mulher enfrenta devem ser compreendidas tendo em vista as expectativas e representações dessa sociedade.
Assim, transformações tais como a queda dos hormônios, as mudanças nas relações interpessoais, na identidade pessoal e nos papéis sociais desempenhados pela mulher refletemse em como ela é percebida e valorizada em diferentes domínios da sociedade, tornando-a objeto de estudo e de intervenções de diferentes disciplinas. No entanto, e infelizmente, é na Medicina que essa mulher tem tido um lugar privilegiado. Neste contexto, a TRH e os antidepressivos têm sido utilizados em muitos casos de modo indiscriminado, em detrimento de uma atenção e escuta da subjetividade e das relações.

O presente estudo mostra que a ciência psicológica tem um papel a exercer, contribuindo para que a passagem pela meia-idade seja vivenciada como crescimento pessoal. A participação em grupos terapêuticos e psico-educativos cresce em importância na medida em que permite à mulher, por meio do compartilhamento de experiências, a resignificação dessa etapa da vida.

Segundo nossa experiência profissional com mulheres de baixa renda no serviço público de saúde, as intervenções clínicas nestes espaços podem resultar em benefícios para as participantes, contribuindo para que a vivência da meiaidade se torne um momento de vida menos sofrido e mais criativo. Conhecer e trocar sua experiência com outras mulheres inseridas num contexto sociocultural semelhante e que também estejam vivendo as demandas da meia-idade pode ajudar no acolhimento do sentimento de solidão e estranheza. Consciente de si, a mulher passa a compreender que o evento da menopausa implica questões muito peculiares e que existe grande diversidade nas maneiras individuais de lidar com esse momento de vida. Ciente de que pode receber uma escuta apropriada num espaço que acolhe singularidades, as mulheres poderão expressar-se genuinamente em seu cotidiano.

\section{Referências}

Beauvoir, S. de. (1980). O segundo sexo: A experiência vivida (S. Milliet, Trad.). Rio de Janeiro: Nova Fronteira. (Original publicado em 1949)

Borysenko, J. (2002). A mulher de 0 a 90 (e além): Os ciclos femininos sob o ponto de vista da biologia, da psicologia e da espiritualidade (R. Jungmann, Trad.). Rio de Janeiro: Record. Nova Era. (Original publicado em 1996)

Ciornai, S. (1999). Da contracultura à menopausa: Vivências e mitos da passagem. São Paulo: Oficina de Textos.

Coelho, V. L. D \& Hollanda, D. M. (2002). Quando o usuário é autor: Reflexões sobre depoimentos redigidos por indivíduos com esquizofrenia. Jornal Brasileiro de Psiquiatria, 51(6), 341-352.

Del Priore, M. (2000a). Corpo a corpo com a mulher: Pequena história das transformações do corpo feminino no Brasil. São Paulo: Senac (Série Ponto Futuro).

Del Priore, M. (2000b). História das mulheres no Brasil ( $3^{\mathrm{a}}$ ed.). São Paulo: Contexto. Del Priore, M. (2001). Histórias do cotidiano. São Paulo: Contexto.

Deutsch, H. (1960). La psicologia de la mujer (5 $5^{\mathrm{a}}$ ed.). Buenos Aires: Editorial Losada. (Original publicado em 1945) 
Diniz, G. (1999). Condição feminina - fator de risco para a saúde mental? Em M. G. T. Paz \& A. Tamayo (Orgs.), Escola, saúde e trabalho: Estudos psicológicos (pp. 181-197). Brasilia: Editora UnB.

Engel, M. (2000). Psiquiatria e feminilidade. Em M. Del Priore (Org.), História das mulheres no Brasil ( $3^{a}$ ed., pp. 322-361). São Paulo: Contexto.

Faria, M. M. (1995). Mulheres de "meia-idade": Sua inserrão nos serviços de saúde. Dissertação de Mestrado não-publicada, Curso de Pós-Graduação da Faculdade de Saúde Pública, Universidade de São Paulo. São Paulo, SP.

Fechtig, A. (2000). Menopausa: Fase de transição? (I. W. Knapp \& M. Scoss, Trads.). São Paulo: Cultrix. (Original publicado em 1998)

Freire, S. A. \& Resende, M. C. (2001). Sentido de vida e envelhecimento. Em A. L. Neri (Org.), Maturidade e velhice: Trajetórias individuais e socioculturais (pp. 71-97). Campinas, SP: Papirus.

Furtado, A. M. (2001). Um corpo que pede sentido: Um estudo psicanalítico sobre mulheres na menopausa. Revista Latino Americana de Psicopatologia Fundamental, IV (3), 27-37.

Goldfarb, D. C. (1998). Corpo, tempo e envelhecimento. São Paulo: Casa do Psicólogo.

Greer, G. (1994). Mulher: Maturidade e mudança (A. F. Antezana, Trad.). São Paulo: Augustus. (Original publicado em 1991)

Kolata, G. (2002). Risk of breast cancer halts hormone replacement study. The New York Times. [On-line]. Disponível: http:// site.mumsweb.com/article.php?sid=759.

Landau, C., Cyr, M. G. \& Moulton, A. W. (1998). O livro completo da menopausa: Guia da boa saúde da mulher (H. Lanari, Trad.). Rio de Janeiro: José Olympio. (Original publicado em 1994)

Laznic, M. C. (2001). Sexualidade feminina e menopausa. Revista da Associação Psicanalitica de Curitiba: Envelhecimento, uma perspectiva psicanalitica, V(5), 59-87.

Loureiro, M. C. (1997). Histerectomia: Possíveis alterações sexuais e influências do nível sócio econômico. Revista Psicologia Ciência e Profissão, 17(3), 12-19.

Marraccini, E. M. (1999). Mulber: Significados no meio da vida. Dissertação de Mestrado não-publicada, Departamento de Psicologia Clínica, Pontifícia Universidade Católica de São Paulo. São Paulo, SP.

Menegon, V. S. M. (1998). Menopausa: Imaginário social e conversas no cotidiano. Dissertação de Mestrado não-publicada, Instituto de Psicologia, Pontifícia Universidade Católica de São Paulo. São Paulo, SP.

Miranda, S. M. R. C. (1996). Tempo de viver: Uma análise dos significados do climatério na mulher favelada. Dissertação de Mestrado não-publicada, Instituto de Psicologia, Pontifícia Universidade Católica de São Paulo. São Paulo, SP.

Mori, M. E. (2002. A vida ou Vida: A escuta psicológica e a saúde da mulber de meia-idade. Dissertação de Mestrado não-publicada, Departamento de Psicologia Clínica, Instituto de Psicologia, Universidade de Brasília. Brasília, DF.
Nissim, R. \& Araújo, M. J. O. (2001). Dossiê menopausa. Retirado em 21.10.2001 da RedeSaúde - Rede Nacional Feminista de Saúde e Direitos Reprodutivos, no World Wide Web:bttp:// mnnu.redesaude.org.br/dossies/html/dossiemenopausa/btml

Pnad-IBGE, Pesquisa Nacional por Amostra de Domicílios. (2001, Dezembro 16). Jornal O Globo, p. 39.

Ramos, D. (1998). Viva a menopausa naturalmente. São Paulo: Augustus.

Sanchez, M. \& Roel, I. (2001). El processo de envejecimiento en la mujer. Retirado em 21.02.2001 da Revista Tiempo, El portal de la Psicogerontología (8), no World Wide Web: wnm.psicomundo.com/tempo8

Simões, R. D. \& Baracat, E. C. (1999). Climatério: Mitos e realidades. Em L. Galvão \& J. Díaz (Orgs.), Saúde sexual e reprodutiva no Brasil (pp. 366-384). São Paulo: Hucitec.

Soares, C. N. (2000). Depressão puerperal, tensão pré-menstrual e depressão na menopausa. Em L. Beny, O. P. Almeida, R. Fráguas Jr. \& E. C. Miguel (Orgs.), Depressão no Ciclo da Vida (pp. 144-155). Porto Alegre: Artmed.

Soares, C. N., Almeida, A. M. M. \& Silva, M. F. G. (1995). Depressão e menopausa: Um século após a "melancolia climatérica". Revista de Psiquiatria Clínica, 22(2), 45-50.

Sommer, B., Avus, N., Meyer, P., Ory, M., Madden, T., Kagawa-Singer, M., Mouton, C., Rasor, N. \& Adler, S. (1999). Attitudes toward menopause and aging across ethnic/racial groups. Psychosomatic Medicine, 61, 868-875.

Tadini, V. (2000). Sexo depois dos 45. Retirado em 30.10 .2000 do Jornal da Unicamp. Universidade Estadual de Campinas, SP, no World Wide Web: http:// wnm.unicamp.br/unicamp/unicamp_boje/ju/out2000/pagina10e11-Ju155.btml

Trien, S. F. (1994). Menopausa, a grande transformação: O livro completo e definitivo sobre a fase mais silenciosa e mais fecunda da vida da mulher (M. T. M. Cavallari, Trad.) $\left(3^{\mathrm{a}}\right.$ ed.). Rio de Janeiro: Rosa dos Tempos. (Original publicado em 1986)

Winnicott, D. W. (1990). O ambiente e os processos de maturacão: Estudos sobre a teoria do desenvolvimento emocional (I. C. S. Ortiz, Trad.) ( $3^{\mathrm{a}}$ ed.). Porto Alegre: Artes Médicas. (Original publicado em 1979)

Winnicott, D. W. (1996). Tudo comeşa em casa (P. Sandler, Trad.). São Paulo: Martins Fontes. (Original publicado em 1986)

Sobre as autoras

Maria Elizabeth Mori é Psicoterapeuta, Especialista em Teorias Psicanalíticas e Mestre em Psicologia, Pesquisadora Associada da Universidade de Brasília (UnB).

Vera Lucia Decnop Coelho é Professora aposentada do Instituto de Psicologia da Universidade de Brasília (UnB) e Pesquisadora associada adjunta da UnB. 


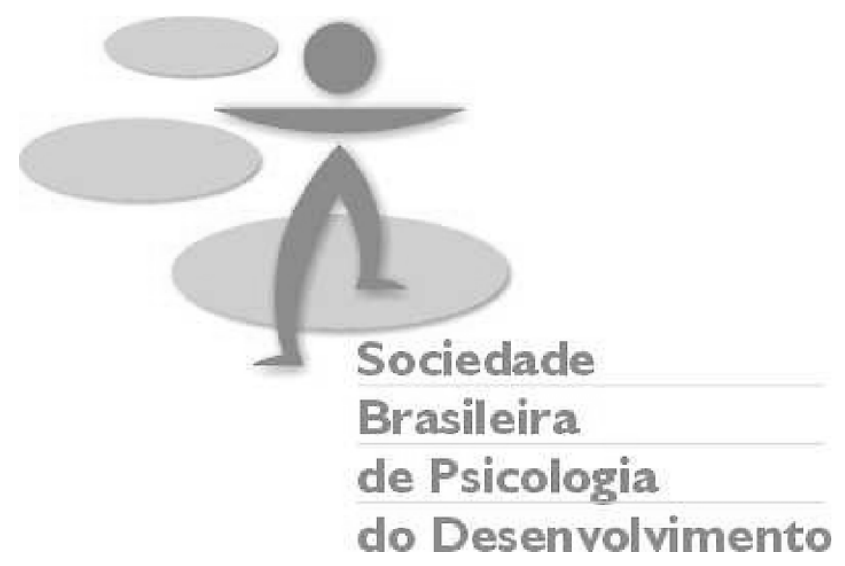

A SBPD é uma entidade de âmbito nacional, de caráter científico, que visa à divulgação e ao aprimoramento da Psicologia do Desenvolvimento, congregando psicólogos, pesquisadores, professores e estudantes de psicologia e áreas afins.

Diretoria 2002/2004

Presidente: Antonio Roazzi (UFPE)

Vice-presidente: Ana Cecília de Sousa Bastos (UFBA)

Primeira Secretária: Débora Dalbosco Dell'Aglio (UFRGS)

Segunda Secretária: Lidia Natalia Dobrianskyj Weber (UFPR)

Tesoureira: Lucia Rabello de Castro (UFRJ)

Associe-se à SBPD e você receberá os exemplares de 2004 da revista:

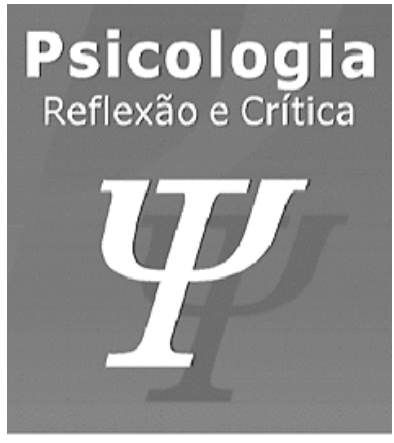

Mais informações:

Sociedade Brasileira de Psicologia do Desenvolvimento

Caixa Postal 18526

CEP 90480-970

Porto Alegre - RS

e-mail para contato: sbpd@cpovo.net

Home-page: http://www.geocities.com/sbpd_2000 